\title{
CÂTEVA OBSERVAȚII ÎN LEGĂTURĂ CU FRAGMENTELE CERAMICE DE PROVENIENȚĂ ROMANĂ ÎN VESTUL BANATULUI DE CÂMPIE
}

Călin Timoc

\section{Einige Bermerkungen zu den im westlichen Raum des Banats entdeckten Keramikscherben römischer Herkunft}

Ein Großteil der aus dem Barbarikum stammenden römischen Funde besteht aus Keramikscherben. Die feinen Waren römischer Herkunft, wie Amphoren, gestempelte polierte Keramik und Terra Sigillata wurden von den Forschern als Importprodukte gedeutet, als Luxusgeschirr der barbarischen Aristokratie.

Aufgrund einer Analyse der im Donau-Theiss-Raum entdeckten Terra-Sigillata-Funde konnten die Forscher belegen, dass der Handel mit Luxusgeschirr aus den Limesprovinzen auch dieses Gebiet beeinflusst hat. Aus diesem Grund lassen sich die Tonscherben der unterschiedlichen römischen Luxusgefäße (aus dem 1.-2. Jh.), die im 3.-4. Jh. im barbarischen Umfeld des Römischen Reiches auftauchen, sind nur schwerlich als Importware zu deuten. Bei manchen Funden handelt es sich um einzelne Tonscherben, die sich nicht in die Kategorie der lokalen (zu Bruch gegangenen) Gebrauchskeramik einordnen lassen.

Einige dieser Funde sind an ihrer Bruchstelle mit Schleifspuren versehen, ein Sachverhalt, der auf eine Neuverwendung der Scherben hinweist. Diese Tatsache deutet darauf hin, dass die späten Sarmaten die Scherben der schönen polierten Luxusgefäße römischer Herkunft als Rohstoff wieder verwendet haben. Das Erscheinungsbild dieser Keramikgegenstände gibt uns Grund zur Annahme, dass es sich hier wohl nur um Spielsteine handeln kann.

$\mathrm{Ob}$ die Sarmaten aus römischen Keramik Teile eines römischen Spieles angefertigt haben? ... das können wir nur vermuten. Es ist bekannt, dass die barbarischen Völkerschaften, die nahe des Limes lebten, von dem römischen „Lifestyle” in großem Maße beeinflusst waren.

Doch Trifunovici, der die sarmatischen Funde aus Ratsko ausgegraben hat, ist der Meinung, dass es sich eher um ein barbarisches Spiel handelt, bei dem die Steine verschiedener Farben und Formen auf eine Linie oder einen Stock geworfen wurden. Gewinner der Runde war jener Spieler, dem es gelang, den Spielstein am nächsten zum Ziel zu werfen.

Die römischen Keramikscherben wurden zur Spielsteinanfertigung gewählt, da ihre intensive rote oder weiß-gelbliche Farbe auf dem Spielplatz leicht zu bemerken und zu verfolgen war.

Cuvinte cheie: Vestul Banatului de Câmpie, epoca romană, ceramică.

Stichwörter: Donau-Theiss-Raum (die Banater Ebene), Römerzeit, Keramik.

Relațiile economice dintre Imperiul roman şi Barbaricum în ,zona de contact” au fost puse în evidență printr-o paletă largă de descoperiri: monede, fibule, ceramică şi vase romane din bronz. Dacă schimburile comerciale sunt reflectate de cantitatea şi calitatea acestor mărfuri romane tranzacționate în mediul extra fines Imperii, felul în care aceste relații economice au afectat stilul de viață tribal al barbarilor din zona limitrofă statului roman a fost mai greu de observat. 
În general, se acceptă părerea că, față de alți barbari mai depărtați de granițele statului roman, cei din zona limesului erau mai evoluați din punct de vedere al tradițiilor sociale şi economice, deoarece au preluat mai uşor influențele romane ${ }^{1}$.

În rândurile de mai jos ne vom opri asupra unor categorii de piese ceramice, de certă factură romană, ce au fost recuperate din săpăturile arheologice în aşezările de sec. II-IV p.Chr. din zona vestică a Banatului de câmpie. Nu de rare ori descoperirile de fragmente de ceramică tipic romană (în câmpia bănățeană la Timişoara-Cioreni, Timişoara-Freidorf, Criciova, Biled, Iecea Mică, Sânicolaul Mare, Alibunar, Kuvin, Subotica etc.) sunt considerate importuri din Imperiul roman, etalonul unor elite locale ${ }^{2}$. Starea extrem de fragmentară de conservare, precum şi raritatea lor în ansamblul ceramicii recoltate nu pot indica un comerț cu asemenea vase, nici măcar existenţa unei elite barbare care poseda asemenea veselă.

Cel mai elocvent exemplu în acest sens îl reprezintă aşezarea sarmatică de la Foeni. Cercetat parțial situl arheologic de sec. II-IV oferă deja o cantitate importantă de informații arheologice. Din cantitatea de ceramică descoperită în câteva locuințe s-a putut observa că predomină ceramica lucrată la roată fină şi semifină, cea lucrată cu mâna fiind destul de rară ${ }^{3}$.

În cadrul ceramicii lucrate la roată, bine arsă şi fațetată, frecvența fragmentelor de vase romane este destul de consistentă, acestea fiind în special din categoria vaselor mici pentru servit masa, ce au putut pătrunde pe calea schimburilor cu provinciile învecinate. Nu lipsesc dintre cioburi şi fragmentele de terra sigillata, care nu mai reprezintă o noutate pentru mediul sarmatic. Andreea Vaday împreună cu Dénes Gabler au strâns toate descoperirile de terra sigillata din spațiul dintre Tisa şi Dunăre şi surprind într-o statistică faptul că majoritatea descoperirilor de importuri de terra sigilatta tip Drag. 37, databile în sec. III p.Chr., originare de pe limes-ul renan, din centrele de producție de la Westerndorf şi Rheinzabern ${ }^{4}$. Totuşi, situația poate să fie una înşelătoare. Aceste vase au circulat şi în imediata vecinătate a graniței provinciilor dunărene. Din păcate însă în cercetările arheologice de la Foeni au apărut doar cioburi mici, singulare, care nu pot fi încadrate tipologic. Inclusiv în complexele închise, cercetate cu mare atenție, nu au putut fi descoperite mai multe fragmente dintr-un vas de lux roman (terra sigillata sau imitații). Situație pare să fie identică şi la Freidorf, unde cantitatea de piese ceramice romane este şi mai redusă ${ }^{5}$.

Ne vine greu să credem că sarmații din Banat achiziționau cioburi de vase de lux din Imperiul roman şi nu vase întregi!

Pe de altă parte ştim că în cazul sarmaților din zona sudică ,a pungii iazyge” nu poate fi vorba de elite care să-şi fi dorit asemenea vase, iar în Banat nu a fost atestat în sec. II-III p.Chr. vreun centru de putere iazyg. Mai târziu, în secolul IV, când ştim că migraţia roxolanilor şi alanilor din a doua jumătate a secolului III p.Chr. intensifică luptele ${ }^{6}$, dar şi locuirea sarmatică în zonă (Banatul de câmpie se umple de aşezări), semn al unuia sau mai multe centre de putere, nu se mai produce la scară industrială terra sigillata în Imperiul roman, locul ei fiind luat de ceramica fină ştampilată ${ }^{7}$.

Puținele indicii pe care le avem sugerează faptul că fragmentele ceramice romane erau folosite de sarmați în alte scopuri. Ceea ce barbarii apreciau la aceste cioburi era calitatea pastei şi culoarea intensă, vie (roşu-purpuriu, portocaliu sau alb-gălbui).

\footnotetext{
${ }^{1}$ Opreanu 1998, 127.

${ }^{2}$ Micle 2001, 129.

${ }^{3}$ Timoc, Szentmiklosi 2008, 117-118.

${ }^{4}$ Gabler, Vaday 1986, 32.

${ }^{5}$ Benea 1997, 73.

${ }^{6}$ Nemeth 2007, 226-227.

${ }^{7}$ Gudea, Filip 1997, 72.
} 
Două fragmente ceramice, unul de formă pătrată dintr-o pastă fină (Fig. 5a), cărămiziuportocalie şi un ciob mai mare (Fig. 5b) dintr-o amforă cărămizie cu slip alb-gălbui, descoperite la Foeni, prezintă urme de şlefuire. Fragmentele ceramice au fost strunjite pe canturile tăioase pentru a putea fi manevrate ulterior cu siguranță, fără să existe pericolul tăierii. Forma de jeton de joc, precum şi marcajul (o virgulă incizată) pe care îl are una dintre piese indică faptul că erau folosite de sarmaţi pentru divertisment.

Dacă piesele realizate din ceramică romană erau utilizate pentru un joc roman, gen ludus latrunculorum, rămâne doar o probabilitate pe care o luăm în calcul (dar atâta vreme cât nu putem aduce argumente în favoarea aculturației acestor triburi barbare din zona de limes, rămâne o simplă presupunere). Un semn de întrebare se ridică însă, de ce nu preferau barbarii ca şi romanii jetoanele din os?

Stanko Trifunovic identifica în aşezările sarmatice târzii din zona Dunării slovene piese asemănătoare cu cele de la Foeni, strunjite din ceramică roşie, dar rămâne la părererea că jetoanele fac parte din cadrul unor jocuri barbare ce se desfăşurau în aer liber şi în văzul mulțimii. Participanții la joc aruncau felurite cioburi din ceramică spre un băț sau o linie, iar cel care reuşea să plasese propriul ,puc” cât mai aproape de țintă câştiga runda. Bineînțeles, regula de bază a jocului (pentru a nu exista neînțelegeri sau confuzii pentru public în legătură cu învingătorul) era ca piesele să fie de culori sau forme diferite, pentru a se putea individualiza fiecare aruncare pe teren ${ }^{8}$.

Datele sunt încă insuficiente pentru a concluziona în legătură cu funcționalitatea acestor piese sau cu practica barbarilor de a colecta cioburi din vase romane pentru a le reutiliza apoi ca materie primă pentru alte activităţi. Este necesar în momentul de față să fie cercetate şi publicate mult mai multe materiale din diversele aşezări de secol II-IV p.Chr., din vestul Banatului de câmpie, pentru a avea o imagine mai clară.

\section{BIBLIOGRAFIE}

Benea 1997 - D. Benea, Quelques observations sur la céramique de l'agglomeration daco-romaine de Freidorf-Timişoara, Études sur la céramique romaine et daco-romaine de la Dacie et de la Mésie Inférieure, Timişoara, 55-76.

Gabler, Vaday 1986 - D. Gabler, A. H. Vaday, Terra Sigillata im Barbaricum zwischen Pannonien und Dazien, Budapest.

Gudea, Filip 1997 - N. Gudea, C. Filip, Vase ştampilate de la Porolissum (II), ActaMN 21, 51-219.

Micle 2001 - D. Micle, Câteva observații privind descoperirile de ,terra sigillara" în aşezările rurale din Dacia de sud-vest, In memoriam Dumitru Tudor (ed. Doina Benea), Timişoara, 129-133.

Nemeth 2007 - E. Nemeth, Politische und militärische Beziehungen zwischen Pannonien und Dakien in der Römerzeit, Cluj-Napoca.

Opreanu 1998 - C. H. Opreanu, Dacia romană şi Barbaricum, Timişoara.

Timoc, Szentmiklosi 2008 - C. Timoc, Al. Szentmiklosi, Câteva date despre ceramica descoperită la Foeni-Seliş̧te (jud. Timiş), AB S.N. 6, 113-134.

Trifunivic 1996 - S. Trifunovic, Sloveni žive u Panoniji još od antičkog doba, http://www.rastko.rs/arheologija/strifunovic-sloveni_panonija.html

\footnotetext{
${ }^{8}$ Trifunovic 1996, http://www.rastko.rs/arheologija/strifunovic-sloveni_panonija.html
} 


\section{LISTA ILUSTRAȚIILOR}

Fig. 1 - Fragmente de ceramică romană ştampilată şi terra sigillata din aşezarea de sec. II-IV p.Chr. de la Freidorf (jud. Timiş), după Micle 2001, 113.

Fig. 2 - Cioburi de ceramică fină roşie şi imitaţii de terra sigillata de la Foeni - Selişte (jud. Timişs).

Fig. 3 - Diverse cioburi de ceramică de lux romană de la Foeni.

Fig. 4 - Fragmente atipice de ceramică roşie ştampilată de la Foeni.

Fig. 5 - Jetoane de joc fabricate din cioburi de ceramică romană din aşezarea sarmatică de la Foeni. 


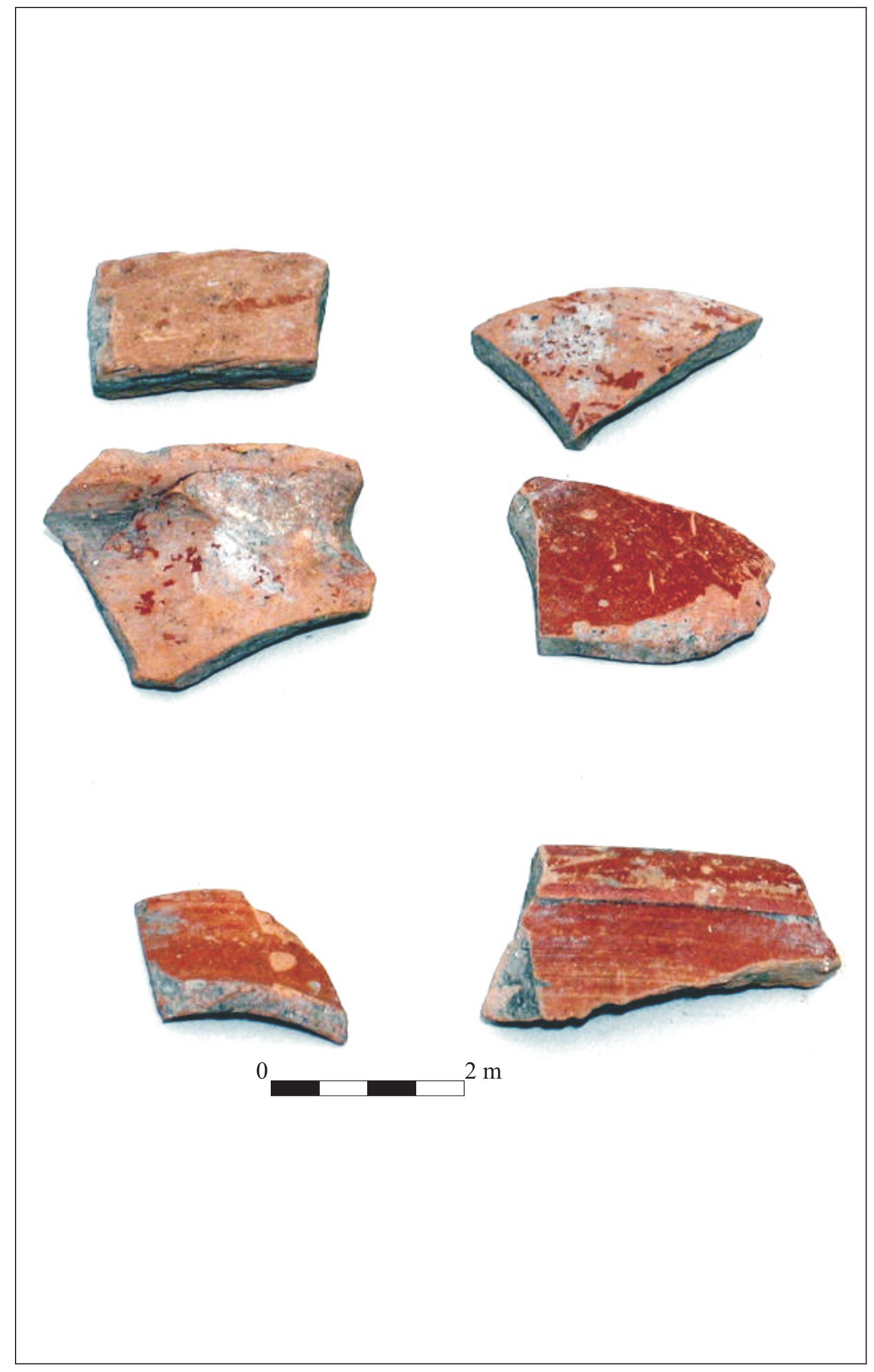

Pl. 1 


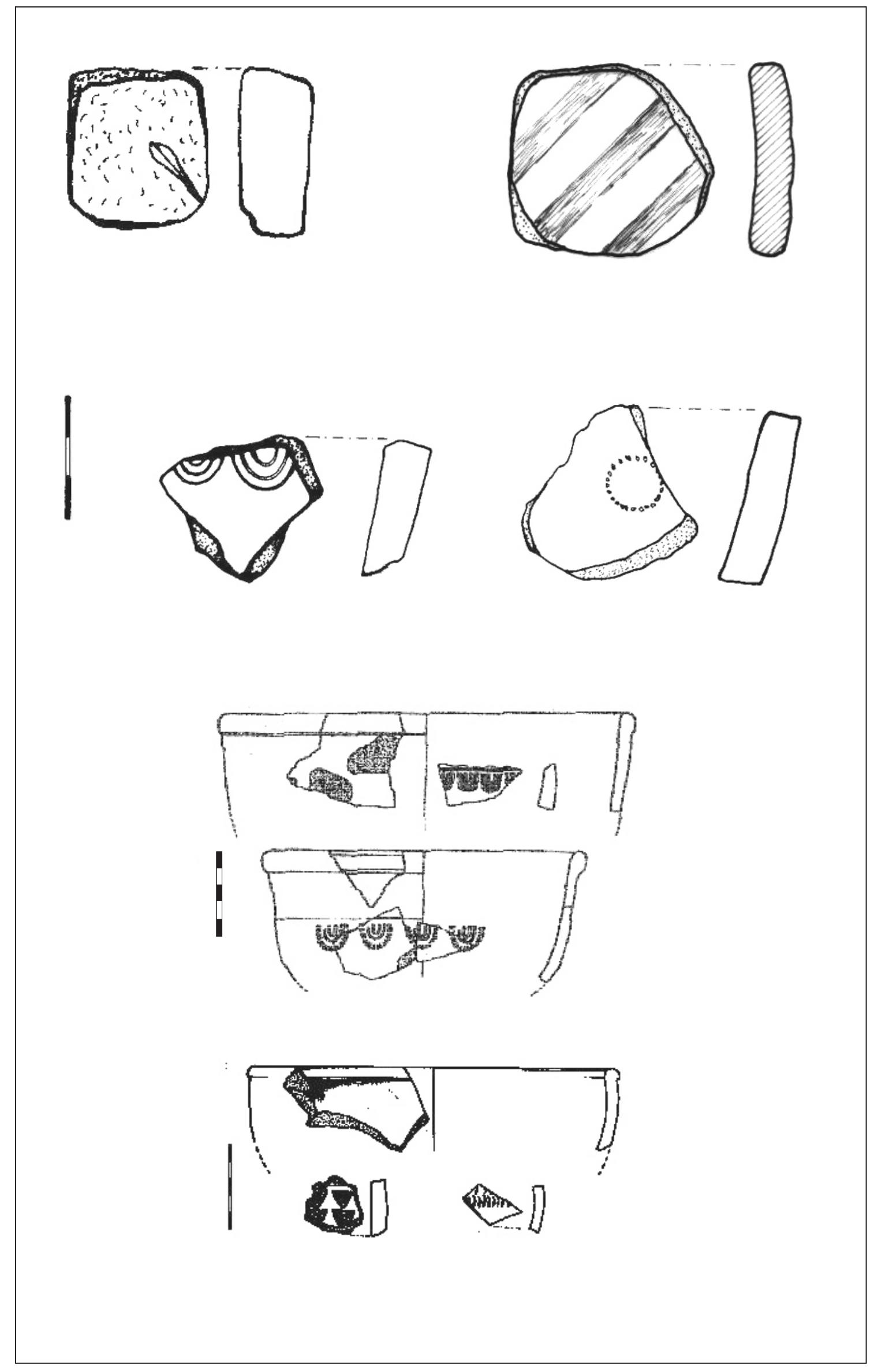

PI. 2 